\title{
O historiador enquanto leitor: história da historiografia e leitura da história*
}

\author{
The historian as a reader: history of historiography and the reading of history
}

\author{
Fernando Nicolazzi \\ f.nicolazzi@hotmail.com \\ Professor adjunto \\ Universidade Federal do Rio Grande do Sul \\ Avenida Bento Gonçalves, 9500 - Agronomia \\ 91501-970 - Porto Alegre - RS \\ Brasil
}

\section{Resumo}

Este ensaio parte de uma sugestiva colocação feita por Manoel Luiz Salgado Guimarães a respeito dos procedimentos de pesquisa para a história da historiografia. Ao sugerir que a atenção voltada para os textos e suas condições de produção supõe sempre a existência de um "certo tipo de leitor", o autor traz para o primeiro plano da investigação o tema da leitura da história. Nesse sentido, partindo da hipótese de que a legitimidade do discurso historiográfico reside não apenas no cumprimento dos protocolos de escrita efetivados pelo historiador, mas também no ato correlato da leitura realizada por seus leitores, este texto oferece um estudo sobre as considerações a respeito da leitura da história feitas pelo historiador e antiquário francês Claude-François Menestrier em sua obra Les divers caracteres des ouvrages historiques, publicada em 1694.

\section{Palavras-chave}

História da historiografia; Erudição; Claude-François Menestrier.

\begin{abstract}
This essay has as its starting point a suggestive statement made by Manoel Luiz Guimarães Salgado about the research procedures used in the history of historiography. By suggesting that the attention usually given to historical texts and their conditions of production always presupposes the existence of a "certain kind of reader", the author brings to the foreground the issue of the reading of history. Based on this assumption that the legitimacy of historiographical discourse lies not only in the historian's compliance with written protocols, but also in the intellectual performance of readers, this text offers a study of the reflections on historical reading developed by the French historian and antiquarian Claude-François Ménestrier in his work Les divers characters ouvrages des historiques, published in 1694.
\end{abstract}

\section{Keywords}

History of Historiography; Historical Scholarship; Claude-François Menestrier.

Recebido em: 15/7/2013

Aprovado em: 17/8/2013

\footnotetext{
* Este ensaio se insere no projeto "Erudição, ceticismo, historiografia: a cultura histórica francesa no século XVI (Bodin, Montaigne, La Popelinière)", financiado pelo CNPq na modalidade de Bolsa de Produtividade em Pesquisa. Agradeço aos amigos Rodrigo Turin e Pedro Telles da Silveira pela leitura e pelos comentários feitos ao texto.
} 
"Não basta falar ou escrever, cumpre ainda ser ouvido ou lido".

Chaim Perelman e

Lucie Ollbrecht-Tyteca

\section{Clio e seus leitores}

A história é uma filha ressentida. Ela não aprecia muito os laços familiares que a ligam a seu pai.

Nosso pobre pai, como vocês sabem - lamenta ela -, não se ocupava quase nunca conosco. Tinha hábitos deploráveis [...] Eu, a história, estou obrigada a dizer tudo e a não ignorar muitas coisas. Nosso pobre pai nunca estava em casa. Nossa (pobre) mãe era muito infeliz. É necessário dizê-lo?, nosso pai estava sempre em busca de aventuras. Sempre enredado em alguma história de saias (PÉGUY 1961, p. 101).

Os leitores de Cícero, para quem o pai da história seria Heródoto de Halicarnasso, não devem se enganar: a história que profere estas amargas palavras não é aquela do saber livresco que hoje se toma como evidência, mas sim Clio, a musa mitológica filha da memória, fruto da desditosa relação entre Mnemosine e Zeus.

Tal ressentimento talvez tenha tornado a história uma leitora mais exigente que o ordinário. Comprova-se isso por meio das considerações por ela tecidas em torno da leitura feita sobre os poemas épicos de Homero, o aedo inspirado pelas musas e de onde, é possível assim sugerir, o saber histórico emergiu na narrativa de Heródoto (HARTOG 2000a; 2000b). Sua leitura avalia traduções, julga as edições, condena os exageros e estipula os parâmetros para um "leitor ideal". No entendimento de Clio, "a leitura é ela mesma uma operação, uma colocação em prática, uma passagem ao ato, que não é de forma alguma indiferente, nula, que não é ausência de atividade, uma passividade pura, uma tábula rasa". Ainda nas suas palavras, "a leitura é um ato comum, a operação comum daquele que lê e daquilo que é lido, da obra e do autor, do livro e do leitor, do autor e do leitor". Consequência marcante disso é o fato de que, para a musa, um texto apenas encontra seu significado pleno na prática da leitura: "ela não é menos que a verdadeira, a autêntica, inclusive, e, sobretudo, a real culminação do texto, a real culminação da obra" (PÉGUY 1961, 104-106).

Estas considerações, para além da sua aparente banalidade, fazem pensar em uma questão ao mesmo tempo evidente e pouco problematizada: a história, não a musa, mas aquela que é escrita pelo historiador, é ela mesma algo dado a ler. É possível ainda dizer mais: ela apenas encontra sua completude, ou seja, apenas é tornada legítima através do gesto complexo daquele que a lê - a culminação de que falava Péguy através da voz de Clio. Ou seja, na produção do discurso histórico, na realização plena da "operação historiográfica" (CERTEAU 1975, p. 63-121) que define esta forma específica de saber, não é forçoso estabelecer uma relação intrínseca entre a legitimação do discurso e a prática da leitura, ainda que nos contornos traçados por Michel de Certeau ao definir aquela operação, a leitura seja justamente o termo ausente da reflexão, embora objeto de preocupações as mais variadas desde o humanismo renascentista (NICOLAZZI 2010). 
Leitor atento da obra do historiador francês, Manoel Luiz Salgado Guimarães não deixou passar despercebida a importância do tema para a prática historiográfica em geral e, particularmente, para o âmbito da história da historiografia. "Se nosso trabalho de investigação supõe os textos escritos, em sua materialidade, como a fonte por excelência da reflexão a ser desenvolvida, a história do livro e da leitura pode trazer algumas sugestivas indicações para este trabalho." E na sequência do argumento, uma sugestão inspiradora dada pelo autor, quando considera que "reconstituir as condições de produção e de possibilidade do texto significa igualmente reinscrevê-lo no cenário em que foi produzido, em diálogo com outros textos e supondo um certo tipo de leitor" (GUIMARÃES 2005, p. 33, grifo meu). Não seria exagero sugerir que ele próprio se enquadrava nesta categoria e, na condição de historiador, ocupava o lugar de "um certo tipo de leitor". Justamente ele que apreciava tanto a leitura e que, por vezes, deixava de lado, para um segundo momento, a tarefa também fundamental da escrita. Sobre isso já se disse que "Manoel Luiz Salgado Guimarães pode ter escrito menos do que se esperava dele, e mais, talvez, do que tenha desejado. Ele gostava mais de ler, ensinar e orientar do que de escrever. [Para ele] escrever era parar de ler" (CEZAR; KNAUSS 2011, p. 18).

Mas que leitor de "certo tipo" é este, qual a sua especificidade? O que espera ele de um texto historiográfico e qual sua atitude diante dele? Se a escrita da história vem há tempos definindo o ofício dos historiadores, quais as implicações da reflexão que procura perceber a dimensão complementar da tarefa, isto é, pensar o historiador enquanto leitor, mas também os leitores da história? Tais indagações, nascidas da própria atividade de leitura, nortearão as considerações esboçadas abaixo, ecoando, ainda que de forma lacunar, a sugestão dada por Manoel Salgado Guimarães.

\section{Leitura e legitimação do discurso histórico}

Ler ou ouvir uma história é um evento tão antigo quanto a própria existência humana. Se, como Carlo Ginzburg já sugeriu, os caçadores foram os primeiros narradores de uma história, eles também foram, por conseguinte, os primeiros que leram uma história através dos rastros deixados pela caça. Seguindo a reflexão do historiador italiano,

talvez a própria ideia de narração tenha nascido pela primeira vez numa sociedade de caçadores, a partir da experiência da decifração das pistas [...] O caçador teria sido o primeiro a 'narrar uma história' porque era o único capaz de ler, nas pistas mudas (se não imperceptíveis) deixadas pela presa, uma série coerente de eventos (GINZBURG 1989, p. 152).

A leitura do sinal deixado pela marca da futura presa criava as condições para se estabelecer a ligação entre um antes e um depois, de onde veio a caça e para onde ela foi.

No plano da história ocidental, creio que dois casos podem ser mencionados como momentos fundadores para o tema aqui ensejado. O primeiro deles, espécie de cena inaugural, remonta ao banquete que 
os feácios ofereceram a Ulisses em um dos episódios mais marcantes de seu périplo em retorno a Ítaca. Em tal ocasião, o herói grego de tal modo sensibilizou-se com o canto do aedo Demódoco, que narrava os feitos do próprio Ulisses no confronto contra os troianos, a ponto de verter lágrimas e chamar a atenção dos presentes para a sua sincera comoção. Em seguida, é o próprio herói quem se converte em narrador, revelando seu nome (até então desconhecido pelos convivas), e contando os infortúnios por que passou desde a partida de Tróia até a chegada como um náufrago na Feácia (Homero, Odisseia VIII-IX). O segundo caso, talvez não menos poético, mas ainda assim relevante, é a cena de Tucídides chorando ao ouvir as histórias narradas por seu ilustre predecessor de Halicarnasso. Tal emoção, segundo consta, teria sido importante na sua decisão de, por inspiração herodoteana, narrar a guerra entre atenienses e peloponesos, tornando-se, com isso, um autor decisivo na definição da história enquanto um saber elaborado por meio de indícios (GAGNEBIN 1997). Ou seja, entre as lágrimas de Ulisses e as lágrimas de Tucídides, passando pelo marco fundador que foi Heródoto, o saber histórico pôde se constituir em seus fundamentos principais: uma narrativa sobre feitos passados, amparada no uso controlado dos rastros deixados no tempo.

O que importa destacar dos dois exemplos mencionados é que, em ambos, o indivíduo que ouviu uma história narrada lançou sobre ela um juízo de valor, acatando (ou não) a validade do relato e atestando (ou não) sua legitimidade enquanto narrativa fidedigna aos fatos. Ulisses avaliza a narrativa do aedo de forma muito particular, considerando que o poeta, ainda que cego, cantava como se tivesse visto com seus próprios olhos:

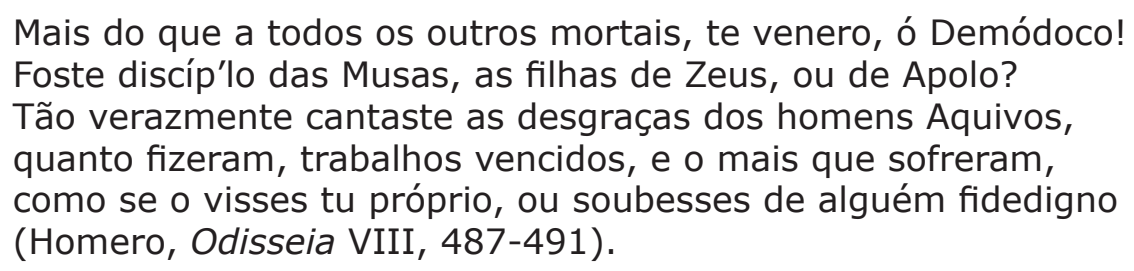

Já Tucídides, na definição de seu próprio percurso, julga problemática a postura dos "logógrafos" (entre os quais Heródoto) que contavam suas histórias tão somente para entreter as plateias. Em famosa passagem da sua Guerra do Peloponeso, escreveu o historiador grego:

com base nos indícios que foram enunciados, entretanto, não erraria quem, de modo geral, julgasse dessa maneira aquilo que eu expus e não desse crédito maior nem ao que fizeram os poetas adornando seus hinos com o intuito de engrandecê-los, nem ao que os logógrafos compuseram visando ao que é mais atraente para o auditório de preferência ao que é verdadeiro (Tucídides, Guerra I, XXI, 1).

Como se percebe, em um contexto ainda marcado sobremaneira pela oralidade, o viajante e o historiador desempenharam o papel crítico que hoje é esperado para os leitores da história. Ulisses, ouvinte antes que narrador, validou 
ou, nos termos aqui intentados, legitimou o relato de Demódoco, uma vez que se tratava dos próprios feitos por ele sofridos e realizados na guerra de Tróia. Discípulo das musas, o poeta "verazmente" cantou algo diante do que não estava presente, mas que pôde ser respaldado pelo choro convulsivo do herói de Ítaca. Para François Hartog, "a presença de Ulisses, lá e cá, atesta que 'aquilo' realmente aconteceu". As consequências são sublinhadas pelo historiador francês: "desenha-se assim uma configuração até então inédita, uma 'anomalia', já que na epopeia a veracidade da fala do aedo depende inteiramente da autoridade da Musa, que é ao mesmo tempo inspiradora e fiadora" (HARTOG 2003, p. 21). A "anomalia" reside justamente no deslocamento operado nesta cena, fazendo passar as condições de atestação do relato, anteriormente situadas ao lado das Musas com seu saber onisciente, ao olhar humano, mesmo que atribuído a um personagem desprovido da visão. "Para Ulisses, por uma curiosa reviravolta, é a visão humana que, pelo menos durante esses três versos, torna-se o padrão pelo qual se pode medir a justeza da visão divina. Tem-se portanto a justaposição de um Demódoco 'aedo' e de um Demódoco 'historiador', mesmo que este último aí apareça somente pelo tempo de 'autenticar' o outro, o aedo" (HARTOG 2003, p. 24).

Em Tucídides, ouvinte de Heródoto, a audição assume um tom crítico que o faz recortar a história legítima, pautada no acesso aos indícios e às testemunhas dignas de fé, daquela elaborada tão somente como forma de divertimento, e não como uma séria "aquisição para sempre". Resulta disso o tom mais direto com que sua narrativa é elaborada, sem oferecer aos leitores os meios pelos quais seguir a construção dos argumentos por ele realizados. Como advertiu Francisco Murari Pires,

a narrativa historiográfica tucidideana não faz aflorar a dialética de suas fontes informativas, e tampouco revela os procedimentos de sua metodologia crítica porque derivou a reconstituição dos fatos consagrados na redação de sua história [...] O discurso narrativo tucidideano é predominantemente, senão avassaladoramente, composto por impressões de apenas resultados factuais, quaisquer que sejam as identificações dos informantes e quaisquer que sejam as operações analíticas de uma sua suposta crítica averiguadora de veracidade (PIRES 1999, p. 280-281).

A consequência disso, através deste "ocultamento do historiador" e, por conseguinte, dos próprios princípios heurísticos que conduziram sua investigação, é a tentativa de aproximar o leitor do objeto narrado, transformando o ato da leitura em uma espécie de visão do acontecido. A autópsia, enquanto procedimento que coloca a visão como eixo investigativo (HARTOG 2005), ocupa este duplo lugar: ao mesmo tempo ela é condição para a prática do historiador e resultado ao qual este almeja alcançar. O "ver com seus próprios olhos" passa a ocupar o lugar tanto do historiador quanto do seu leitor. Assim, em um mesmo gesto, ao colocar historiador e leitor no mesmo plano, Tucídides provoca também uma situação relevante: quando confere o registro da utilidade da boa história como "aquisição para sempre", define igualmente o papel assumido pelo bom leitor da história: aquele que não busca tão somente o divertimento, mas úteis lições para a vida. ${ }^{1}$

\footnotetext{
${ }^{1}$ Não se quer com isso criar uma falsa justaposição entre a história como "aquisição para sempre" e o modelo
} 
O modelo de história pragmática de Políbio parece se estabelecer em conformidade com esta sugestão, como se percebe, por exemplo, em sua denúncia voltada para "impedir que em história a mentira possa se impor da mesma forma que a verdade". Assim, ao criticar historiadores que se ocuparam com a narrativa da guerra de Cleómenes, estabelece seu alvo em Filarco que, segundo ele, teria escrito procurando antes alcançar a simpatia dos leitores do que escrever a verdade sobre os fatos. Para Políbio, "o historiador não deve buscar emocionar o leitor com a ajuda de cenas comoventes; também não the cabe emprestar aos personagens as palavras que eles teriam podido pronunciar, nem de tirar, à maneira dos poetas trágicos, todos os efeitos possíveis de uma situação" (Políbio, Histoire II, 56, 2-10). Dessa maneira, ao definir sua história a partir do gênero pragmático, Políbio recorta também o tipo de leitor específico ao qual ela é destinada: aquele com espírito político, preocupado antes com a utilidade da história do que com o possível prazer provocado por ela (Políbio, Histoire IX, 1, 1-6)

Entre os antigos ainda, o escritor satírico Luciano de Samosata deixou para a posteridade aquele que é reconhecido hoje como o mais antigo tratado sobre a escrita da história (pelo menos entre aqueles a que nós modernos tivemos acesso). Em seu Como se deve escrever a história, título destinado a ter vida longa em suas pequenas variações, Luciano escreveu a partir das histórias que leu e ouviu, elaborando, dessa maneira, um juízo crítico a respeito da forma de receber os relatos sobre eventos passados. Um trecho é significativo dessa posição. $\mathrm{O}$ autor sugere que a função da história, ligada ao registro do verdadeiro, deve se mostrar distante do simples panegírico. Nas suas palavras,

nela [na história], o completamente fabuloso e o elogio voltado exageradamente para um só lado não são prazerosos para os ouvintes, se você não pensa na chusma e na massa do povo, mas, por Zeus! naqueles que o ouvirão como juízes e acusadores, aos quais nada passaria despercebido, por lançarem um olhar mais agudo que o de Argos por todas as partes do corpo e avaliarem cada coisa dita como se fossem cambistas, de modo a rejeitar imediatamente o que for falso, recebendo as moedas verdadeiras, legal e perfeitamente cunhadas (Luciano Como, 10). ${ }^{2}$

A analogia do ouvinte com o cambista é relevante em função do olhar apurado e, sobretudo, treinado que é demandado a este, afinal ele é, no exercício da sua profissão, aquele capaz de distinguir o falso do verdadeiro, a boa moeda daquela forjada com o intuito de ludibriar uma das partes da relação. Como se sabe, o trabalho do bom falsário possui inúmeras, ainda que nem sempre reconhecidas, proximidades com o do crítico (GRAFTON 1990).

De qualquer forma, estes poucos e dispersos exemplos oriundos da antiguidade servem aqui para indicar a questão proposta: se parte do intuito do historiador ou daquele ocupado em relatar eventos do passado é elaborar um

ciceroniano de historia magistra vitae, ainda que aproximações entre elas sejam possíveis.

${ }^{2} \mathrm{Na}$ edição da Loeb Classical Library, é significativa a forma como o tradutor definiu o público ideal da história: "those who will listen in the spirit of judges and indeed of fault-finders as well" (LUCIANO, Works VI).O leitor aqui é também aquele ocupado em "encontrar os erros" (fault-finders) do registro lido. 
discurso legítimo, obedecendo aos princípios e requisitos que, de tempos em tempos, são normalmente aceitos como condições suficientes para se confiar na veracidade do registro elaborado, da qual é dependente a possível utilidade da história, a legitimidade esperada não se limita apenas à tarefa de elaboração do registro (no caso dos historiadores, à escrita da história), mas ocupa igualmente, e de forma mais importante do que se costuma supor, o âmbito da prática da leitura da história. O "certo tipo de leitor" a quem o texto historiográfico é dirigido, personagem que, assim como a escrita da história, apenas pode ser percebido quando situado historicamente, é também aquele capaz de atestar sua validade, conferindo a ele credibilidade e depositando nele uma confiança sem a qual todo o esforço se encontraria injustificado. É na leitura que a crença na história - crença de que ela diz a verdade e que, portanto, oferece certa utilidade - se manifesta de forma mais cabal. Por conseguinte, pode-se sustentar que a história tem por pretensão menos persuadir o leitor do que convencê-lo, considerando a persuasão como uma "relação de força" em mão única, espécie de imposição àquele que é persuadido (o leitor desempenharia um papel passivo nesta relação), ao passo que o convencimento é uma prática com dupla direção, na qual o próprio leitor, de forma ativa, estabelece sua própria confiança no texto lido (PERELMAN; OLBRECHTS-TYTECA 2005, p. 29 et seq). No fundo, convencer-se da história é acreditar nela; crer na história, eis aí o ponto nodal entre seu escritor e seu leitor. ${ }^{3}$

\section{Claude-François Menestrier e a Introdução à leitura da história}

Saltando direto dos antigos para os modernos, detenho-me em outro caso interessante para a análise. Trata-se do padre jesuíta, historiador e antiquário, especialista em heráldica, Claude-François Menestrier, nascido em 1631, em Lyon, e morto no ano de 1705, em Paris. Autor de uma miríade de escritos, que atravessaram os mais variados temas, publicou em 1659 duas obras sobre o estudo de brasões: Esboço da ciência do brasão e $A$ verdadeira arte do brasão. Dois anos depois, após algumas polêmicas letradas na qual se envolveu, publica A arte do brasão justificada, com "provas e autoridades" que justificavam a prática de estudo sobre os escudos (armoiries). ${ }^{4}$

Em 1694, Menestrier lança o plano de uma nova história da cidade de Lyon, precedido de algumas páginas sobre "os diversos caracteres das obras históricas", que serviriam ao autor para definir com maior precisão o lugar ocupado por sua futura obra (MENESTRIER 1694). O título dado a esta preleção é bastante significativo: Introdução à leitura da história. Sobre os diversos caracteres de todas as espécies de obras históricas. O intuito do autor, que se propõe a escrever uma história que cobriria mais de vinte séculos e abarcaria múltiplas perspectivas sobre a cidade, é estabelecer uma classificação dos tipos

\footnotetext{
${ }^{3}$ Sobre a questão da crença na história, embora seguindo uma perspectiva que, se se aproxima desta em alguns pontos, em outros se mostra bastante distante, remeto a HARTOG 2013.

${ }^{4}$ Para um registro bio e bibliográfico sobre Menestrier, remeto à obra do historiador e arqueólogo Paul-Auguste Allut, Recherches sur la vie et sur les oeuvres du P. Claude-François Menestrier de la compagnie de Jésus. Suivies d'un recueil de lettres inédites de ce père à Guichenon, \& de quelques autres lettres de divers savans de son temps, inédites aussi, publicada em Lyon, no ano de 1856 (ALLUT 1856, p. 1-205).
} 
ou "espécies" possíveis de escrita da história. O dado marcante disso, me parece, é o fato desta taxonomia historiográfica não ser destinada aos historiadores, que já estão bastante esclarecidos para necessitar da sua, como ele próprio diz, "fraca iluminação", mas sim àqueles dispostos a ler seus escritos, isto é, aos leitores da história. Há, é verdade e como de costume, um tom de modéstia afetada na escolha, mas não é menos verdade que se trata de uma opção consciente e que procura trazer para o primeiro plano da discussão o papel importante da leitura da história. Menestrier, assim, como que prepara o leitor para a história que ele próprio projeta escrever, convertendo-se ele mesmo em um leitor das histórias alheias.

A Introdução à leitura da história é algo um tanto distinto daquilo que o leitor atual está acostumado a ver no início de muitos trabalhos historiográficos contemporâneos, ou seja, uma revisão bibliográfica crítica, por meio da qual o autor posiciona sua obra diante de outras surgidas anteriormente. Ali, Menestrier intenta elaborar critérios gerais de classificação das modalidades possíveis da prática historiográfica, os quais se situam, conforme o autor, no âmbito da matéria e no âmbito da forma. No primeiro critério, são classificadas seis modalidades que, em alguns casos, permitem subdivisões: história natural (trata da natureza, mas também de fenômenos considerados sobrenaturais, como monstros, prodígios, espectros etc); história eclesiástica e sagrada (que não podem ser confundidas: a primeira estuda o estabelecimento da Igreja, a outra os atos propriamente divinos); história civil (ocupada com povos, Estados, repúblicas, cidades; subdivide-se em tópica - descrição das cidades; pragmática - reporta as ações; crônica - representa a ordem do tempo; genealógica voltada para as filiações e linhas de descendência); história didascálica (discute a origem das artes e das ciências); história singular (que tanto pode ser a descrição de ações ou intrigas com longa sequência como de uma única e breve ação); e história pessoal (definida como o quadro da vida de uma pessoa). 0 autor menciona ainda a existência de histórias fingidas (histoires feintes), isto é, aquelas "supostas, apócrifas, que são falsas histórias, imposturas e mentiras públicas", colocando neste balaio tanto as obras de Nanni de Viterbo, ${ }^{5}$ quanto os romances, contos, "historietas" escritas sem pretensões de verdade ou com a clara pretensão da mentira (MENESTRIER 1694, p. 30-31).

Quanto à forma, Menestrier estabelece uma divisão mais ampla, ainda que mais confusa. São de início divididas treze formas de se escrever a história: universal; particular; simples; figurada; explicativa (raisonée); autorizada; poética; crítica; apologética; política; moral; jovial; misturada. Destaco a definição de "história simples", considerada como o "relato nu e fiel das coisas passadas, da maneira como elas se passaram, sem nenhum artifício ou ornamento de discurso". Ele insere nesta categoria as crônicas escritas por monges e religiosos que apenas registravam os fatos do seu próprio tempo. Estas crônicas, "que a poeira e os versos ruminaram durante muitos séculos

${ }^{5}$ Sobre o papel de Nanni de Viterbo como um dos primeiros críticos e, curiosamente, notório falsário da historiografia moderna, ver GRAFTON 1990. 
nos arquivos e nas bibliotecas dos antigos monastérios, são agora tesouros e riquezas da história, pois se descobre nelas aquilo que ocorreu em diversos tempos com tanta aparência de verdade que se vê nelas menos de artifício" (MENESTRIER 1694, p. 34-35). Por tais razões, são consideradas a "mina da história", cujos metais em estado bruto ali encontrados deveriam ainda passar por um cuidadoso processo de lapidação.

A "história figurada", por sua vez, é aquela, ao contrário das histórias simples, com algum tipo de "ornamento de espírito e de destreza dos historiadores", mas que não se confunde também com a "história poética", já que, para além da descrição dos fatos, carrega um esforço explicativo no sentido de buscar causas e motivos para os fatos, além de esboçar uma reflexão de caráter político voltada para a condução dos negócios públicos; dessa maneira, destina-se aos sábios e aos "grandes ministros de Estado". É como uma "história explicativa (raisonée) que, sem parar na casca e na aparência das coisas, vai até o pensamento das pessoas que agiram, descobre suas intenções e faz ver sobre o evento coisas em que empreenderam a sabedoria da sua conduta ou o erro de seu julgamento" (MENESTRIER 1694, p. 39). À diferença das histórias poéticas, as figuradas não se valem de "ficções engenhosas, de ornamentos ou de artifícios" meramente inventados, mesmo que nelas seja concedida a possibilidade do uso de figuras ou imagens que lhe dão um caráter alegórico ou simbólico.

Como se percebe, portanto, ainda que a definição do historiador ali seja clara, como aquele que descreve "exatamente as coisas acontecidas e passadas, da maneira como aconteceram" (MENESTRIER 1694, p. 43), as fronteiras entre sua prática e aquela dos poetas, por exemplo, não é tão nitidamente traçada. Trata-se, antes, de um recorte de gênero bastante poroso, onde os limites da invenção não ficam plenamente claros. Assim, a história poética é aquela dos poemas épicos e dos romances, que podem ter um fundo de verdade, mas cujas circunstâncias foram transformadas pelo autor. Tal a importância, então, de um outro gênero ali levantado, a "história crítica", como aquela "que se ocupa de apontar os defeitos dos historiadores que precederam e que escreveram as mesmas coisas que se quer tratar" (MENESTRIER 1694, p. 57). Todavia, mais que uma modalidade voltada para a definição própria da história, se trata de um tipo de postura que objetiva antes a condenação ou o elogio dos historiadores do que de seu próprio escrito. Assim, na "história crítica" julga-se mais o praticante que realizou mal a prática do que o resultado de sua atividade.

Outro tipo de história classificado por Menestrier que merece aqui menção é a "história autorizada", ou seja, aquela que, "ao contrário dos ornamentos da história figurada, possui provas que são retiradas da história simples e que ela fornece sem arte para apoiar aquilo que expõe com mais artifício e disposição" (MENESTRIER 1694, p. 60). Continua o autor ressaltando, com plena consciência do momento em que escrevia, que

esta maneira de escrever é particular a este século, que, não amando menos a verdade do que as invenções engenhosas, encontrou os meios de uni-las acrescentando às narrativas explicativas e figuradas (narrations raisonées \& figurées), os títulos, os diplomas (chartes) e os extratos 
de crônicas e de memórias que serviram para seu estabelecimento (MENESTRIER 1694, p. 60).

Menestrier certamente conhecia os esforços da erudição monástica que desempenharam importante papel diante do ceticismo filosófico que ocupou lugar no ambiente francês do século XVII. Jean Mabillon, por exemplo, é citado em outras passagens do texto. Mas sua percepção do contexto vai além disso, ressaltando o papel importante que a publicação e circulação mais efetivas de edições de "velhas crônicas e de histórias antigas" desempenhava em tal momento, tornando mais acessível o contato, não apenas com temas variados, mas também com uma profusão de fontes que permitiria autorizar de forma mais bem fundamentada os escritos historiográficos (cf. BLAIR 2003).

Sem entrar em detalhes sobre os demais gêneros sugeridos por Menestrier, cabe destacar que para ele a história se mostra como a mais importante e vasta das "artes", da qual pretende "sucintamente marcar os diversos caracteres para fazer em resumo toda a enciclopédia da história" e que, espera o autor, tenha tempo para "descrever todas as [suas] partes segundo o método de Aristóteles [usado] para a retórica e para a poética" (MENESTRIER 1694, p. 70). Em outras palavras, o tipo singular de ars historica pretendida pelo autor equivalia a definir para a história sua "essência e [suas] várias espécies, com a função característica de cada uma", tal como o filósofo antigo definiu para a poesia (Aristóteles, Poetics 1447a), ainda que, no caso do historiador de Lyon, a atenção sobre as formas de constituição de enredo não tenham sido sinalizadas no escrito sobre a leitura da história. Da mesma forma, se levarmos em consideração o que o autor grego escreveu em sua Arte retórica sobre o uso do discurso argumentativo pela maioria das pessoas, e como elas fazem isso "de forma aleatória ou com uma familiaridade decorrente de hábito", salientando que, "uma vez que estas duas formas são possíveis, é evidente que as matérias podem ser reduzidas a um sistema" (Aristóteles, Art 1.1, 2), podemos pensar na função das considerações feitas por Menestrier no sentido de constituírem-se enquanto uma technê da história, ou seja, uma espécie de discussão sistemática que, ao mesmo tempo em que favorece o praticante da história, privilegia aqueles a quem ela é endereçada, trazendo a leitura ao primeiro plano da discussão "técnica" sobre a história.

\section{História da historiografia e leitura da história}

A importância da leitura da história, ao menos para autores que sobre ela escreveram entre o período do humanismo renascentista e os primeiros clarões das luzes no século XVIII, residia no caráter central que a tópica magistral formulada por Cícero ainda assumia em tal contexto (KOSELLECK 2006). Para a história ter eficácia enquanto magistra vitae, para que do passado pudessem ser extraídas úteis lições e apropriados proveitosos exemplos, fazia-se necessário um procedimento criterioso de leitura. Afinal, aprender com a história vivida equivalia, até certo ponto, ao aprendizado através da história lida (NICOLAZZI 2011).

Menestrier, nesse sentido, não destoava do ambiente no qual o encontramos. Para ele, a catalogação tão minuciosa quanto possível da história se tornava 
relevante pelo fato de que na tarefa de leitura se demandava um grau elevado de discernimento a fim de "julgar comme il faut as obras histórias". O risco que a falta de cuidado com tal procedimento acarretava era condenar o que deveria ser elogiado ou acusar aquilo que deveria se mostrar objeto de admiração. Dessa maneira, "é preciso, antes de se pronunciar sobre uma obra histórica, examinar cuidadosamente qual a sua matéria e a qual espécie de história a que ela pertence. Qual o fim do autor, e por quais meios ele se dirige para lá" (MENESTRIER 1694, p. 115-116). Cada tipo de história possui suas regras próprias e uma maneira particular pela qual ela deve ser realizada. De igual forma, a expectativa que se pode projetar para determinada história deve levar em consideração a espécie na qual ela se insere. A história genealógica, por exemplo, requer "dedução e a distribuição dos ramos de uma família, sua união com o tronco e a linha direta de descendentes, os nomes, as ocupações, as qualidades e as alianças de todos aqueles que descenderam destas famílias, com os títulos e as provas autênticas"; não pode, por isso, ser confundida com a história de um Estado. Por sua vez, "aquele que empreende a história de uma coisa só [como a história do Concílio de Trento, por exemplo] não é obrigado a seguir as leis da história universal" (MENESTRIER 1694, p. 117). A boa leitura, então, é aquela capaz de separar as coisas e criar as expectativas de acordo com aquilo que lhe é dado a ler; se cada história pressupõe um critério específico para sua escrita, este mesmo critério deve ser levado em consideração no momento em que ela é lida.

Assim, na fauna e flora historiográficas estabelecidas pelo autor francês, tão variadas quanto as espécies de história são as espécies de historiador por ele classificadas. A lista é longa e contam-se dezesseis tipos específicos: historiadores gramáticos (estudam as etimologias dos nomes e palavras), historiadores críticos (examinam peças históricas estabelecendo o recorte entre o verdadeiro e o falso), historiadores poetas (escritores épicos que tomaram da história seus temas poéticos), historiadores historiadores (historiens historiens, "são aqueles que expõem simplesmente e sem artifício a verdade, como os escritores de crônicas") , historiadores oradores (aqueles que inserem discursos, harangues, e outros ornamentos narrativos em seus relatos), historiadores físicos (escrevem história natural), historiadores jurisconsultos (tratam de questões do direito através das histórias), historiadores políticos ("são aqueles que não se propõem apenas descrever o passado, como o resto dos historiadores, mas vêm o presente para regrá-lo e o futuro para prevê-lo e para se preparar para ele com os exemplos do passado"), historiadores morais (fazem considerações sobre os costumes privados das pessoas), historiadores geógrafos (ocupados com as descrições físicas dos países, tal como o fazem os cosmógrafos), historiadores bibliógrafos (criam catálogos de autores e obras), historiadores prosopógrafos (estudam os grupos de pessoas de um determinado Estado), historiadores cronógrafos (seguem a ordem do tempo e de quem depende a fidelidade das datas e da cronologia), historiadores "estematógrafos" (stemmatographes, ${ }^{6}$ 
são aqueles que escrevem história a partir das armas e brasões), historiadores teólogos (voltados para as questões da Igreja, como concílios e assembleias eclesiásticas), historiadores canônicos (canonistes, preocupados com o direito canônico e com as regras da liturgia), historiadores misturados (meslez, que são aquelas que, de acordo com as necessidades da situação, misturam alguns dos gêneros de história já salientadas) (MENESTRIER 1694, p. 118 et seq).

Após todas estas considerações classificatórias, Menestrier passa a elencar suas opções para a escrita da história de Lyon pretendida, em quais fontes ou autores irá buscar suas informações relevantes, oferecendo um juízo crítico sobre os autores que o antecederam em tal empreitada. Ou seja, na sua prática de historiador, a leitura da história aparece como uma condição prévia para a escrita, por meio da qual é efetivada não apenas uma revisão da bibliografia existente, mas uma sistematização classificatória das espécies de história possíveis de serem mobilizadas pelos historiadores. Neste caso em particular, a leitura é, portanto, uma operação taxonômica compreendida dentro do conjunto de tarefas esperadas para a realização plena do ofício.

$\mathrm{Na}$ classificação das histórias realizada por nosso autor, alguns pontos podem ainda ser sugeridos. Em primeiro lugar, é significativo o fato de que não há ali uma historicização da história propriamente dita, isto é, a historiografia não é pensada como uma prática temporalizada. Tal como muitos dos seus contemporâneos e antecessores imediatos, Menestrier, ao citar seus exemplos escolhidos, não parece fazer muita distinção entre um autor da antiguidade clássica e outro que tenha escrito há apenas algumas décadas. É bem verdade que não deixa de reconhecer a diversidade de épocas que separam os autores modernos dos antigos, mas é relevante também notar que, por exemplo, a mesma história universal que encontra Políbio como um de seus fundadores, foi também praticada por Diodoro da Sicília, no século I a.C., e pelo Cardeal Baronius, um dos encarregados dos Anais eclesiásticos publicados no final do século XVI. Ou seja, ainda que a atenção cronológica seja um dos requisitos para a atuação dos historiadores, o tempo não é um fator classificatório das histórias para Menestrier. A plena compreensão da história implica, com isso, antes a atividade de situá-la entre as espécies definidas (no espaço da classificação, por assim dizer) do que colocá-la em perspectiva histórica (portanto, no tempo).

Por outro lado, talvez se possa enxergar na Introdução à leitura da história um exemplo lapidar da pluralidade de histórias que somente a partir da virada do século XVIII para o XIX vão assumir o estatuto de um "singular coletivo" tal como sugerido por Reinhart Koselleck (KOSELLECK 2013; 2006; 1997). As diversas espécies de histórias elencadas não são apenas adjetivações variadas de uma história singular. Em outras palavras, se a forma e a matéria são princípios fundamentais do sistema elaborado pelo antiquário de Lyon, elas não são apenas variantes de uma mesma e singular história; pelo contrário, acabam por conformar uma pluralidade de histórias possíveis que, se assumem o mesmo substantivo designador que a língua latina oferece (afinal, a obra diz respeito à leitura d'a história), não deixam de se apresentar como práticas profundamente variadas. Tal é a razão pela qual, ainda no entendimento de 
Menestrier, a própria figura do historiador é um personagem pluralizado; não se trata de apenas um ator desempenhando múltiplos papéis, mas de diversos autores que, no limite, não fazem necessariamente a mesma coisa, mesmo que um requisito em comum os una pela necessidade de escrever apenas a verdade.

Na distribuição proposta por Menestrier, o recorte entre aquilo que pode ser considerado história e aquilo que não o pode ainda não assumiu os contornos que os séculos seguintes lhe dariam. Cabe lembrar, por exemplo, que algumas décadas depois da publicação de sua obra, Voltaire já realizará, na escrita do verbete história para a Enciclopédia de Diderot e D'Alembert, distinções mais evidentes e que serão mantidas dali por diante: em primeiro lugar, a fábula é expurgada do espaço da disciplina, não cabendo mais nem no invólucro de uma história figurada ou poética; em segundo lugar, à história natural já é imputada uma impropriedade nominal ("impropriamente dita história", segundo o filósofo), sendo empurrada para o âmbito da física (VOLTAIRE 1765, p. 220-221). Ou seja, correlata a uma nova compreensão da história que a converte em um singular coletivo, transformando-a em sujeito dela mesma, parece ocorrer no século XIX também uma singularização dos procedimentos práticos da história: sua autonomia enquanto ciência dependia da definição de critérios homogêneos para a prática, que possibilitassem evitar a pluralização confusa que os séculos anteriores the atribuíam e para a qual Menestrier, como se viu, contribuiu ativamente.

\section{O historiador como leitor}

Voltando ao ensejo deste texto proposto por Manoel Luiz Salgado Guimarães, cabe retomar a ideia de que a história da historiografia, pelo menos aquela ocupada com as condições de produção do texto historiográfico, deveria atentar para a dimensão da leitura da história, procurando refletir sobre o "certo tipo de leitor" que, de fato, realiza esta prática. A obra de Claude-François Menestrier aqui mencionada me parece significativa de uma forma de se lidar com tal questão, fazendo do historiador não apenas aquele que escreve a história, mas igualmente aquele que a tem por objeto de uma leitura também "de certo tipo".7

É evidente que a sua Introdução à leitura da história não é bem uma história da historiografia com a qual os historiadores estão atualmente acostumados, pois é justamente aquilo que define a consciência histórica moderna, ao menos na definição koselleckiana de modernidade que tem se tornado canônica, o que faltava na compreensão do historiador de Lyon: uma compreensão temporalizada da experiência. Todavia, as considerações acima esboçadas fazem pensar em um objeto instigante de estudo: as formas possíveis de historicização da leitura da história, o que permitiria considerar, por conseguinte, que a história da historiografia poderia assumir as vezes de uma leitura temporalizadora sobre a história. Assim, antes do trabalho da escrita efetiva da história, o historiador se converteria em um certo tipo de leitor da história.

\footnotetext{
7 Neste ensaio, como se percebe, a atenção não foi voltada ao estudo das características efetivas deste "certo tipo de leitor", pois isto implicaria em outros procedimentos de análise, sejam eles voltados para as formas de recepção dos textos historiográficos, sejam voltados para os modos pelos quais os próprios historiadores estabelecem, em seus textos, um leitor implícito.
} 


\section{Referências bibliográficas}

ALLUT, Paul-Auguste. Recherches sur la vie et sur les oeuvres du P. ClaudeFrançois Menestrier de la compagnie de Jésus: suivies d'un recueil de lettres inédites de ce père à Guichenon, \& de quelques autres lettres de divers savans de son temps, inédites aussi. Lyon: Imprimerie de Louis Perrin, 1856.

ARISTÓTELES. Art of rethoric. Translated by J. H. Freese. Loeb Classical Library, vol. XXIII. Cambridge: Harvard University Press, 1926.

. Poetics. Translated by Stephen Halliwell. Loeb Classical Library, vol. XXII. Cambridge: Harvard University Press, 1995.

BLAIR, Ann. Reading strategies for coping with information overload, ca. 15501700. Journal of the History of Ideas, vol. 64, n. 1, 2003.

CEZAR, Temístocles; KNAUSS, Paulo. O historiador e o viajante: itinerário do Rio de Janeiro a Jerusalém. In: GUIMARÃES, Manoel Luiz Salgado. Historiografia e nação no Brasil, 1838-1857. Rio de Janeiro: Eduerj, 2001.

FURETIÈRE. Antoine. Dictionnaire universel contenant generalement tous les mots françois tant vieux que modernes, \& des termes de toutes les sciences et des arts. Paris, 1690.

GRAFTON, Anthony. Forgers and critics: creativity and duplicity in Western scholarship. Princeton: Princeton University Press, 1990.

GUIMARÃES, Manoel Luiz Salgado. Historiografia e cultura histórica: notas para um debate. Ágora, Revista de História e Geografia (Santa Cruz do Sul), v. 11, n. 1, 2005.

HARTOG, François. A fábrica da história: do "acontecimento" à escrita da história. As primeiras escolhas gregas. História em Revista, v. 6, 2000 a.

. The invention of history: the pre-history of a concept from Homer to Herodotus. History and Theory, v. 39, n. 3, 2000 b.

. Primeiras figuras do historiador na Grécia: historicidade e história. In: 2003. . Os antigos, o passado e o presente. Brasília: Editora da UNB,

. L'oeil de Thucydide et I'histoire véritable. In: . Evidence de

I'histoire: ce que voient les historiens. Paris: Gallimard, 2005.

. Croire en I'histoire. Paris: Flammarion, 2013.

HOMERO. Odisseia. Tradução de Carlos Alberto Nunes. Rio de Janeiro: Ediouro, 2004. KOSELLECK, Reinhart. L'expérience de I'histoire. Paris: Gallimard, Le Seuil, 1997. . Historia magistra vitae: sobre a dissolução do topos na história moderna em movimento. In: Futuro passado: contribuição à semântica dos tempos históricos. Rio de Janeiro: Contraponto; Editora PUC/RJ, 2006. 
; MEIER, Christian; GÜNTHER, Horst; ENGELS, Odilo. O conceito de história. Belo Horizonte: Autêntica, 2013.

LUCIANO. Works. Vol. VI. Translation by K. Kilburn. Loeb Classical Library. Cambridge: Harvard University Press, 1959.

Como se deve escrever a história. Tradução de Jacyntho Lins Brandão. Belo Horizonte: Tessitura, 2009.

MENESTRIER, Claude-François. Les divers caracteres, des ouvrages historiques avec le plan d'une nouvelle histoire de la ville de Lyon: le jugement de tous les autheurs qui en ont écrit, \& des dissertations sur la fondation, \& son nom; sur le passage d'Annibal, la division des champs, le titre de colonie romaine, \& les deux tables, d'airain de I'Hôtel de Ville. Lyon: J.-B. et N. de Ville, 1694.

NICOLAZZI, Fernando. Como se deve ler a história? Leitura e legitimação na historiografia moderna. Varia História, vol. 26, no. 44, 2010.

Como se deve ler a história: Jean Bodin e a ars historica do século XVI. In: NICOLAZZI, Fernando; MOLLO, Helena Miranda; ARAUJO, Valdei Lopes de. (orgs.). Aprender com a história? O passado e o futuro de uma questão. Rio de Janeiro: Editora FGV, 2011.

PÉGUY, Charles. Clio. Dialogue de I'histoire et de l'âme païenne. In:

Oeuvres complètes en prose. Vol. 2. Bibliothèque de la Pléiade. Paris: Gallimard, 1961.

Clío: diálogo entre la historia y el alma pagana. Buenos Aires: Cactus, 2009.

PERELMAN, Chaim; OLBRECHTS-TYTECA, Lucie. Tratado da argumentação: a nova retórica. São Paulo: Martins Fontes, 2005.

PIRES, Francisco Murari. Mithistória. São Paulo: Humanitas Publicações, 1999.

POLÍBIO. Histoire. Traduction de Denis Roussel. Paris: Gallimard, 2003.

TUCÍDIDES. Guerra do Peloponeso. Livro I. Tradução de Anna Lia Amaral de Almeida Prado. São Paulo: Martins Fontes, 1999.

VOLTAIRE. Histoire. In: Encyclopédie, ou dictionnaire raisonné des sciences, des arts et des métiers, par une societé de gens de lettres. Tome VIII. Neufchastel, 1765. 